\title{
The Effectiveness of Coping Strategies in the Latent First Stage of Labour: A Systematic Review
}

\author{
Maria Luisa Rega ${ }^{1 *}$, Casasanta Daniela ${ }^{2}$, Burlon Barbara ${ }^{3}$, Gori Cecilia ${ }^{1}$, Damiani Gianfranco $^{4}$ \\ and Anderson Gloria ${ }^{1}$ \\ ${ }^{1}$ Master's Degree in Nursing and Midwifery Sciences, Italy \\ ${ }^{2}$ Occupational Medicine, Health Directorate, Italy \\ ${ }^{3}$ Coordinator OU Obstetrics and Delivery Room, Italy \\ ${ }^{4}$ A Gemelli IRCCS University Hospital Foundation, Italy \\ *Corresponding author: Maria Luisa Rega, Master of Science in Nursing and Midwifery, Catholic University of the Sacred Heart, L \\ go Francesco Vito 1 - 00168, Rome, Italy
}

\section{ARTICLE INFO}

Received: 幽 December 18, 2019

Published: January 06, 2020

Citation: Maria Luisa R, Casasanta D, Burlon B, Gori C, Damiani G, et al., The Effectiveness of Coping Strategies in the Latent First Stage of Labour: A Systematic Review. Biomed J Sci \& Tech Res 24(2)2020. BJSTR. MS.ID.004020.

Keywords: Coping Strategies; Educational Interventions; Latent Phase of Labour; Pregnant Mother; Woman in Labour; Personalized Treatment

Abbreviations: CSPL: Coping Strategies Performed in Labour; CSTP: Coping Strategies Taught in Pregnancy; CINAHL: Cumulative Index to Nursing and Allied Health Literature; PICO: Population, Intervention, Comparison and Outcome; CBSEI: Childbirth Self-Efficacy Inventory; PBI: Present Behavioral Intensity

\section{ABSTRACT}

Introduction: Coping strategies performed in labour or taught in pregnancy reduce women's pain and anxiety, enhancing women' self-efficacy. To identify which are the most appropriate coping strategies health care providers should implement to help women cope with a prolonged latent phase of labour.

Materials and Methods: A systematic review was carried out during December 2018 on MEDLINE - Pubmed, CINAHL, Web of Science PsycINFO, and Scopus. All of the RCTs assessing the effects of coping strategies during the latent phase of labour on primiparous or nulliparous women aged 16 or above were included. We independently reviewed the selected studies and extracted data using predefined criteria including samples, interventions, timings and outcomes.

Results: 3591 studies were identified, of which 8 met the inclusion criteria. Two main groups of coping strategies were found: Coping Strategies Performed in Labour (CSPL) or Coping Strategies Taught in Pregnancy (CSTP). The CSPL included manual or relaxation techniques delivered during labour, which were associated with a decrease of pain intensity and anxiety levels. The CSTP included educational interventions provided during the third trimester of pregnancy, which were aimed to improve women's selfefficacy and knowledge about labour. Efficacy of educational interventions wasn't consistent among all studies, but self-efficacy was higher in women educated on relaxation techniques, while pain was lower in women educated on both manual and relaxation techniques.

Discussion: More high-quality research is needed regarding which groups of coping strategies is more effective, paying attention on the measurement tools, outcomes and health care providers involved.

\section{Introduction}

The latent phase of labour is defined as a period of time marked by painful uterine contractions and variable changes of the cervix, including some degree of cervical effacement and a slow dilatation up to $5 \mathrm{~cm}$ [1]. The timing of the latent phase of labour can vary widely from one woman to another, possibly depending on physiological or pathological causes but also on psychological factors like the woman's emotions and sensibility to the environment [2]. Since the certain duration of the latent phase has not yet been established [1], uncertainty and waiting may amplify women's fear and anxiety [3]. The timing of hospitalization is often subjected to women's self-evaluation and needs for reassurance or support [4]. An early hospitalization may lead to a series of unnecessary medical interventions to accelerate the latent phase of labour [5], which are not recommended by WHO [1]. However, 
WHO [1] does recommend the use of coping techniques, such as relaxation or manual techniques, for the management of women's pain and anxiety during latent phase. Indeed, the ability of women to endure pain or anxiety in labour is related to the perceived level of support and knowledge [4,6], which could be enhanced by working on their coping skills. Coping is defined by Lazarus \& Folkman [7] as the person's cognitive and behavioral efforts meant to manage situations that are perceived as stressful. During a prolonged latent phase of labour the coping efforts could serve as powerful resources [8] in the management of anxiety and pain [9]. However, which of these coping techniques are the most adequate to ease the management of women's latent phase of labour is not clear yet [10]. Therefore, the purpose of this systematic review was to identify which are the most appropriate coping strategies health care providers should implement to help women cope with latent phase of labour.

\section{Materials and Methods}

\section{Literature Search Strategy}

A systematic review of the literature was carried out to identify randomized [RCT] controlled trials assessing the effects of coping strategies during the latent phase of labour. A detailed search strategy was developed, based on the Population, Intervention, Comparison and Outcome (PICO) approach [11] and the recommended guidelines for the reporting of systematic reviews and meta-analyses [12]. Systematic searches of the following online databases were conducted in December 2018: MEDLINE/ PubMed; Cumulative Index to Nursing and Allied Health Literature (CINAHL); Web of Science; PsycINFO; Scopus. Bibliographic search was restricted to studies reported in English. Search records were managed in Zotero.

\section{Eligible Criteria}

All randomized [RCT] controlled trials assessing the effects of coping strategies during the latent phase of labour on primiparous or nulliparous women aged 16 or above were included. Following the WHO recommendations on intrapartum care [1] (2018), we included in our review all manual or relaxation techniques for pain management during the phase of labour, as well as all educational interventions for coping enhancement delivered by a midwife or a nurse during pregnancy. In accordance with literature findings, the primary outcomes chosen were pain, self-efficacy and anxiety $[1,3,9]$. The exclusion criteria were high risk pregnancy, pre-term birth, infective disease and psychiatric illness.

\section{Study Selection and Quality Assessment}

After removal of duplicates, titles and abstracts of all retrieved search, records were independently screened by two reviewers [GA, DC] for meeting inclusion criteria. Full text of studies included were then retrieved and reviewed for final selection. Disagreements were resolved through consultation with a third reviewer [MLR]. Two reviewers [CG, BB] independently rated the methodological quality of all included studies using the Revised Cochrane risk-ofbias tool for randomized trials (RoB 2) [13]. As recommended by the RoB 2 guidelines, risk of bias was described and assessed for all primary outcomes evaluated in each study (Supplemental File 1\#). Any disagreements about the methodological quality were resolved through consensus.

Supplement File 1\#: Studies details for assessment of the methodological quality using the Revised Cochrane risk-of-bias tool for randomized trials ( $\operatorname{RoB} 2)$.

\begin{tabular}{|c|c|c|c|}
\hline \multicolumn{4}{|c|}{ Outcome assessed for risk of bias: Pain } \\
\hline Reference & Study design & Numerical result being assessed & Team's aim for the result \\
\hline Chang et al [17], Taiwan & RCT & $p=0.000$ & assignment to intervention \\
\hline Duncan et al. [15] USA & RCT & $p=0.15$ & assignment to intervention \\
\hline Escott et al. [21] UK & Cluster RCT & $\mathrm{p}=0.88$ & assignment to intervention \\
\hline Ip et al. [18] Hong Kong & RCT & $\mathrm{p}=<0.001$ & assignment to intervention \\
\hline Kimber et al. [22] UK & Placebo RCT & 95\% confidence interval (CI) & assignment to intervention \\
\hline Liu et al. [19] Taiwan & RCT & $\mathrm{p}=<0.001$ & assignment to intervention \\
\hline Maimburg et al. [16] Denmark & RCT & $p=0.43$ & assignment to intervention \\
\hline \multicolumn{4}{|c|}{ Outcome assessed for risk of bias: Anxiety } \\
\hline Reference & Study design & Numerical result being assessed & Team's aim for the result \\
\hline Chang et al [17], Taiwan & RCT & $p=0.04$ & assignment to intervention \\
\hline Ip et al. [18] Hong Kong & RCT & $\mathrm{p}=<0.001$ & assignment to intervention \\
\hline Liu et al. [19] Taiwan & RCT & $\mathrm{p}=0.09$ & assignment to intervention \\
\hline \multicolumn{4}{|c|}{ Outcome assessed for risk of bias: Self-efficacy } \\
\hline Reference & Study design & Numerical result being assessed & Team's aim for the result \\
\hline Duncan et al. [15] USA & RCT & $\mathrm{p}=0.4$ & assignment to intervention \\
\hline Escott et al. [21] UK & RCT & $\mathrm{p}=0.58$ & assignment to intervention \\
\hline Ip et al. [18] Hong Kong & RCT & $\begin{array}{l}\mathrm{p}=0.92 \\
\mathrm{p}=0.64\end{array}$ & assignment to intervention \\
\hline Rahimparvar et al. [20] Iran & RCT & $\mathrm{p}=0.001$ & assignment to intervention \\
\hline
\end{tabular}




\section{Data Extraction and Analysis}

For all included studies the following data was extracted: bibliographic details, study population and sample size, intervention, timing and follow up, participation of the partner, outcomes measured and related tools (Table 1). Studies' interventions were further analysed to identify the coping strategy employed and whether it was taught in pregnancy (CSTP) or directly performed in labour (CSPL) by the midwife or the nurse [14]. If present, the conceptual model or framework behind the intervention was indicated.

Table 1: Summary characteristics of studies included in systematic review $(\mathrm{N}=8)$.

\begin{tabular}{|c|c|c|c|c|c|c|c|}
\hline $\begin{array}{l}\text { Author, Year, } \\
\text { Country }\end{array}$ & Sample & Intervention & Timing & Outcomes & Measurement & $\begin{array}{l}\text { Validation of } \\
\text { tool }(Y / N)\end{array}$ & $\begin{array}{c}\text { Quality } \\
\text { assessment }\end{array}$ \\
\hline \multirow{2}{*}{$\begin{array}{l}\text { Chang et al. [17], } \\
\text { Taiwan }\end{array}$} & \multirow{2}{*}{$\begin{array}{l}42 S \\
41 C\end{array}$} & \multirow{2}{*}{$\begin{array}{c}\text { Massage Programme } \\
\text { VS } \\
\text { Standard Nursing Care }\end{array}$} & \multirow{2}{*}{ Labour } & Pain & $\begin{array}{l}\text { Present Behavioural } \\
\text { Intensity (PBI) }\end{array}$ & $\mathrm{Y}$ & Some concerns \\
\hline & & & & Anxiety & $\begin{array}{l}\text { Visual Analogue Scale } \\
\text { for anxiety (VASA) }\end{array}$ & $\mathrm{Y}$ & High risk \\
\hline \multirow[b]{2}{*}{$\begin{array}{l}\text { Duncan et al. } \\
\text { [15] USA }\end{array}$} & \multirow[b]{2}{*}{$\begin{array}{l}15 S \\
15 C\end{array}$} & \multirow{2}{*}{$\begin{array}{c}\text { Mindfulness Training } \\
\text { Educational Programme } \\
\text { VS } \\
\text { Selected Antenatal Classes }\end{array}$} & \multirow[b]{2}{*}{$3^{\text {rd }}$ trimester } & Pain & $\begin{array}{l}\text { Visual Analog Scale } \\
\text { (VAS) }\end{array}$ & $\mathrm{Y}$ & High risk \\
\hline & & & & Self-efficacy & $\begin{array}{l}\text { Childbirth Self-Efficacy } \\
\text { Inventory (CBSEI) }\end{array}$ & $\mathrm{Y}$ & Some concerns \\
\hline \multirow{2}{*}{$\begin{array}{l}\text { Escott et al. [21] } \\
\text { UK }\end{array}$} & \multirow{2}{*}{$\begin{array}{l}35 S \\
45 C\end{array}$} & \multirow{2}{*}{$\begin{array}{c}\text { Coping Strategy } \\
\text { Enhancement Educational } \\
\text { Programme } \\
\text { VS }\end{array}$} & \multirow{2}{*}{$3^{\text {rd }}$ trimester } & Pain & $\begin{array}{l}\text { Present Pain Intensity } \\
\text { (PPI) }\end{array}$ & $\mathrm{Y}$ & High risk \\
\hline & & & & Self-efficacy & 18 item scale & $\mathrm{Y}$ & High risk \\
\hline \multirow{3}{*}{$\begin{array}{l}\text { Ip et al. [18] } \\
\text { Hong Kong }\end{array}$} & \multirow{3}{*}{$\begin{array}{l}96 S \\
96 C\end{array}$} & \multirow{3}{*}{$\begin{array}{c}\text { Standard Antenatal Class } \\
\text { Self-Efficacy Enhancing } \\
\text { Educational Programme } \\
\text { VS } \\
\text { Standard Antenatal Class on } \\
\text { voluntary basis }\end{array}$} & \multirow{3}{*}{$\begin{array}{l}\text { 3rd } \\
\text { trimester }\end{array}$} & Pain & $\begin{array}{l}\text { Visual Analogue Scale } \\
\text { (VAS) }\end{array}$ & $\mathrm{N}$ & Low risk \\
\hline & & & & Anxiety & $\begin{array}{l}\text { Visual Analogue Scale } \\
\text { (VAS) }\end{array}$ & $\mathrm{Y}$ & Low risk \\
\hline & & & & Self-efficacy & $\begin{array}{l}\text { Chinese Childbirth } \\
\text { Self-Efficacy Inventory } \\
\text { Short form (CBSEI) }\end{array}$ & $\mathrm{N}$ & Low risk \\
\hline $\begin{array}{l}\text { Kimber et al. } \\
\text { [22] UK }\end{array}$ & $\begin{array}{l}30 S- \\
30 P \\
30 C\end{array}$ & $\begin{array}{c}\text { Massage Educational } \\
\text { Programme with relaxation } \\
\text { techiniques } \\
\text { VS } \\
\text { Music Programme with } \\
\text { relaxation techniques } \\
\text { VS } \\
\text { Standard Antenatal Classes }\end{array}$ & $3^{\text {rd }}$ trimester & Pain & $\begin{array}{l}\text { Visual Analogue Scale } \\
\text { (VAS) }\end{array}$ & $\mathrm{N}$ & Some concerns \\
\hline \multirow[t]{2}{*}{$\begin{array}{l}\text { Liu et al. [19] } \\
\text { Taiwan }\end{array}$} & \multirow[t]{2}{*}{$\begin{array}{l}51 S \\
54 C\end{array}$} & \multirow[t]{2}{*}{$\begin{array}{c}\text { Music Therapy Programme } \\
\text { VS } \\
\text { Standard Nursing Care }\end{array}$} & \multirow[t]{2}{*}{ Labour } & Pain & $\begin{array}{l}\text { Visual Analogue Scale } \\
\text { for Pain (VASP) } \\
\text { Present Behavioural } \\
\text { Intensity (PBI) }\end{array}$ & $\begin{array}{l}\mathrm{N} \\
\mathrm{Y}\end{array}$ & High risk \\
\hline & & & & Anxiety & $\begin{array}{l}\text { Visual Analogue Scale } \\
\text { for anxiety (VASA) }\end{array}$ & $\mathrm{N}$ & High risk \\
\hline $\begin{array}{l}\text { Maimburg et al. } \\
\text { [16] Denmark }\end{array}$ & $\begin{array}{l}603 S \\
590 C\end{array}$ & $\begin{array}{c}\text { Antenatal Training } \\
\text { Education } \\
\text { VS } \\
\text { Standard Antenatal Class }\end{array}$ & $3^{\text {rd }}$ trimester & Pain & use of pain relief & $\mathrm{N}$ & Some concerns \\
\hline $\begin{array}{l}\text { Rahimparvar et } \\
\text { al. [20] Iran }\end{array}$ & $\begin{array}{l}75 S \\
75 C\end{array}$ & $\begin{array}{l}\text { Educational Software } \\
\text { VS } \\
\text { Routine Prenatal Care }\end{array}$ & $3^{\text {rd }}$ trimester & Self-efficacy & $\begin{array}{l}\text { Childbirth Self-Efficacy } \\
\text { Inventory (CBSEI) }\end{array}$ & $\mathrm{Y}$ & Some concerns \\
\hline
\end{tabular}

\section{Results}

\section{Main Characteristics of the Included Studies}

The literature search generated 3591 references, of which 8 studies met our inclusion criteria. Numbers and reasons for exclusion at each stage are reported in Figure 1. Overall, 1923 women were enrolled in the studies; most of them enrolled a sample ranging from 80 to 200 women, while one study had a sample of just 30 women [15] and another enrolled more than 1000 women [16]. The studies were published between 2002 and 2017, mainly in Asia [17-20] and Europe [16,21,22], while only one study was published in the USA [15]. Except for one [15], all studies reported women's mean age, ranging from 25,2 [20] to 29 [21] 
for the experimental group and from 24,8 [20] to 30 [22] for the control group. Description of sample, intervention, and outcomes is reported in Table 1. All studies described interventions aimed to enhance women's ability to cope with latent phase of labour. The studies were categorized in two main groups, based on the timing of interventions: studies in which the intervention was performed during labour (CSPL) by a health provider to help women cope with latent phase of labour (Table 2), and studies in which an educational intervention was taught during pregnancy (CSTP) (Table 3).

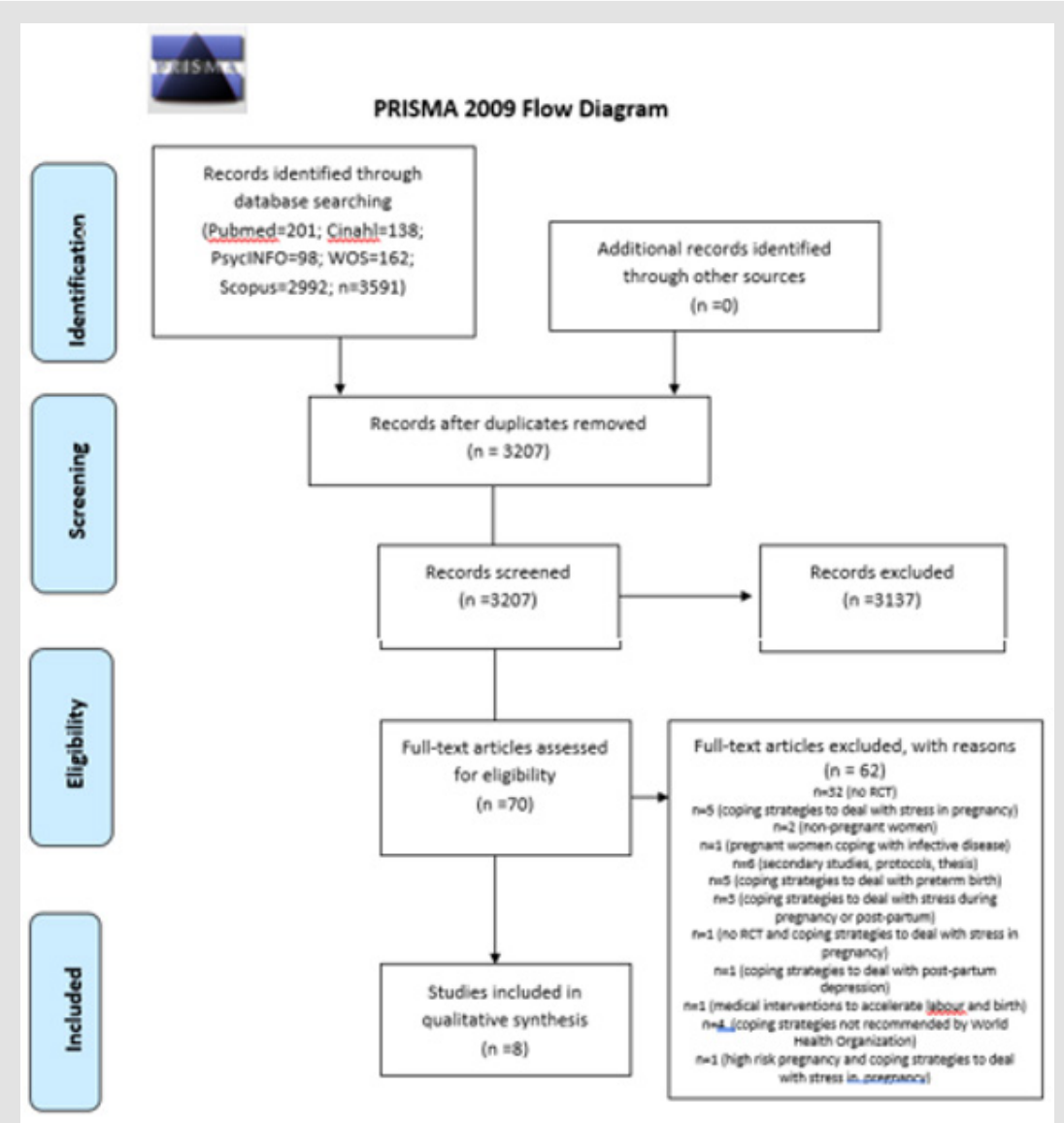

Figure 1: Flow diagram of the study selection process. From: Moher D, Liberati A, Tetzlaff J, Altman DG, The PRISMA Group (2009). Preferred Reporting Items for Systematic Reviews and Meta-Analyses: The PRISMA Statement. PLoS Med 6(7): e1000097.

Table 2: Coping strategies performed in labour (CSPL).

\begin{tabular}{|c|c|c|c|c|}
\hline \multirow{2}{*}{ Reference } & \multicolumn{3}{|c|}{ Coping strategies } & \multirow{2}{*}{ Efficacy } \\
\hline & Technique & Description & Partner (Y/N) & \\
\hline Chang et al [17] & Manual & $\begin{array}{l}\text { Al least two directional, reasonably firm and rhythmic massage lasting } \\
30 \text { minutes and comprising abdominal effleurage, sacral pressure and } \\
\text { shoulder and back kneading. }\end{array}$ & Y & $\begin{array}{c}\text { Pain** } \\
\text { Anxiety ** }\end{array}$ \\
\hline Liu et al. [19] & Relaxation & $\begin{array}{l}\text { Participants were instructed to choose one of the following types of } \\
\text { relaxing, anxiety-reducing music: classical; light; popular; crystal children's; } \\
\text { chinese religious music for at least } 30 \text { minutes during latent phase }\end{array}$ & $\mathrm{N}$ & $\begin{array}{c}\text { Pain** } \\
\text { Anxiety ** }\end{array}$ \\
\hline
\end{tabular}

The CSPL's group included two studies $[17,19]$ in which manual and relaxation techniques, such as massage and music, were performed by the health provider during labour to help women cope with the latent phase of labour. Both these interventions showed a statistically significative decrease on pain and anxiety compared with the control groups, who received routine care only. Moreover, the presence and collaboration of the partner positively influenced the quality of women's labour experience [17]. The CSTP's group included six studies [15,16,18,20-22] where various educational interventions were delivered during the third trimester of pregnancy to improve women's self-efficacy or knowledge about labour and birth experience (Table 3). The relaxation techniques, such as mindfulness or cognitive restructuring of pain (Table 3), were the most commonly taught coping strategies [15,18,20,22]. Sometimes, the relaxation techniques were combined with manual techniques, such as massage $[20,22]$. Some educative interventions were designed to improve women's knowledge on latent phase, giving women's general information on labour or on pain's management $[16,20]$. 
Table 3: Coping strategies taught in pregnancy (CSTP).

\begin{tabular}{|c|c|c|c|c|}
\hline \multirow{2}{*}{ Reference } & \multicolumn{3}{|c|}{ Coping strategies } & \multirow{2}{*}{ Efficacy } \\
\hline & Technique & Description & Partner $(\mathrm{Y} / \mathrm{N})$ & \\
\hline Duncan et al. [15] & Relaxation & $\begin{array}{c}\text { Body scan; Yoga; Meditation; Mindfulness of breath; Partner } \\
\text { touch; Body movements; Sounding; Personalized coping } \\
\text { strategies }\end{array}$ & Y & $\begin{array}{l}\text { Pain- } \\
\text { Self-efficacy } * *\end{array}$ \\
\hline Escott et al. [21] & $\begin{array}{l}\text { Personal coping } \\
\text { strategies }\end{array}$ & $\begin{array}{l}\text { Identification of pre-existing strategies using discussion of } \\
\text { previous pain and panic experiences }\end{array}$ & Y & $\begin{array}{c}\text { Pain* } \\
\text { Self-efficacy* }\end{array}$ \\
\hline Ip et al. [18] & Relaxation & Breathing; Distraction; Cognitive restructuring of pain & $\mathrm{N}$ & $\begin{array}{c}\text { Pain** } \\
\text { Anxiety** } \\
\text { Self-efficacy* }\end{array}$ \\
\hline Kimber et al. [22] & Manual; Relaxation & $\begin{array}{l}\text { The birth partner learnt to perform slow rhythmic long stroke } \\
\text { massage movements using the flats of the hands. These stokes } \\
\text { were combined with slow rhythmic breathing. The woman and } \\
\text { her birth partner were taught to synchronise massage strokes } \\
\text { with controlled breathing. The visualisation/mind mapping } \\
\text { component was taught, by asking the woman to visualize/focus } \\
\text { on the massaging hands. }\end{array}$ & Y & Pain * \\
\hline Maimburg et al. [16] & Knowledge & knowledge on labour; pain relief interventions & Y & Pain * \\
\hline $\begin{array}{l}\text { Rahimparvar et al. } \\
{[20]}\end{array}$ & $\begin{array}{l}\text { Manual; Relaxation; } \\
\text { Knowledge }\end{array}$ & $\begin{array}{l}\text { knowledge on labour; relaxation techniques; respiratory } \\
\text { techniques; massage technique; knowledge on music therapy }\end{array}$ & $\mathrm{N}$ & Self-efficacy $* *$ \\
\hline
\end{tabular}

Note: ${ }^{*}=$ Statistically not significant difference after the intervention between the Experimental Group and the Control Group (Experimental group improvement); ${ }^{*}=$ Statistically significant difference after the intervention between the experimental and the Control Group (Experimental group improvement); - = Statistically not significant difference after the intervention between the Experimental Group and the Control Group (Control group improvement); - - = Statistically significant difference after the intervention between the experimental and the Control Group (Control group improvement).

Teaching women to identify personal pre-existing coping strategies through discussions of previous pain and panic experiences, was an alternative strategy to reduce pain and panic experiences in the latent phase [21]. The participation of the partner was integrated in all the educational interventions except for two $[18,20]$. In general, the CSTP's efficacy wasn't consistent among all studies, due to the variety of the strategies provided and outcomes assessed. Self-efficacy showed to be higher after interventions focused on relaxation techniques, such as Mindfulness and breathing, even when combined with manual techniques $[15,20]$. Pain was assessed for all studies except for one [20] and it seemed to be positively influenced by both manual and relaxation techniques in most studies, although not statistically significative. Only one study assessed anxiety [18], with a significative decrease on the experimental group educated on relaxation techniques.

\section{Quality Assessment}

The methodological quality of all studies was assessed for all the selected primary outcomes and it's reported in Table 4. Only one study [18] showed a low risk of bias for all the outcomes assessed. Two studies $[19,21]$ were evaluated as high risk for both outcomes assessed, while the remaining studies raised some concerns or a high risk of bias for at least one outcome. The risk of deviations from the intended interventions and the risk of bias in the measurement of the outcomes were common in most trials, consequently the overall risk of bias across most of the trials may rise some concerns. For most of the studies, blinding women and health care providers was not possible and reporting indicated that some outcomes may have been influenced by a lack of blinding, being consequently rated at a high risk of bias. The small number of studies within comparisons and lack of high-quality trials indicates that there is currently insufficient evidence to determine which interventions are most appropriate to help women cope with a latent phase of labour. We also downgraded the evidence due to some concerns regarding the selection on the reported results, mostly due to the lack of trails' protocols. In both the interventions delivered during labour compared with controls, we rated evidence for pain and anxiety with an overall high risk of bias. Most of the trials evaluating interventions delivered during pregnancy compared with controls, were graded with "high" or "some concerns" risk of bias for pain or self-efficacy. Only two trails evaluating interventions delivered during pregnancy included anxiety and were graded at high and low risk of bias.

\section{Discussion}

\section{Summary of Main Results}

Our findings suggest that two different groups of coping strategies are appropriate to help women manage latent phase of labour: CSPL $[17,19]$ and/or CSTP [15,16,18,20-22]. The CSPL were a massage technique and a music intervention. These could benefit from an active participation of the women's partners and improve their relationship with the health care provider, without showing evident harmful side effects. The CSPL were well described, given precise instructions regarding how the health care provider should perform the massage technique or which kind of music to play. Both, music intervention and massage technique, were associated with a decrease of pain intensity and anxiety levels during the latent phase of labour (some concerns-quality evidence). Pain intensity 
was assessed in both studies by validated and specific self-reported tools (Present Behavioural Intensity [PBI]) [17,19]. The CSTP were mostly educative interventions aiming to improve women's self-efficacy or knowledge. The CSTP contained a wide array of coping strategies ranging from relaxation techniques, mindfulness interventions, manual techniques, to personal coping strategies of the past or an improvement of women's knowledge on labour.

All the CSTP were given during the third trimester of pregnancy. Most of the CSTP included the women's partner participation. A mindfulness intervention or an improvement of women's knowledge on labour during pregnancy seems to be related to an increase of women's self-efficacy (some concerns-quality evidence). However, these interventions were not associated with a decrease of women's pain in latent phase of labour. Effects of teaching personal coping strategies during pregnancy on pain or self-efficacy were not clear (high risk-quality evidence). The interventions focused on manual techniques or relaxation techniques, such as breathing or visualization techniques, were linked to a decrease of pain or anxiety during the latent phase of labour (low risk-quality evidence/some concern-quality evidence). The CSTP were widely different one to each other, in timing, setting, contents and health care providers delivering the intervention. Though almost all the studies measured women's self-efficacy with a validated self-reported tool (Childbirth Self-Efficacy Inventory [CBSEI]) the measure of labour's pain and anxiety was performed with a broad range of tools. The power of the review to detect meaningful differences between groups and analyses was limited by the small number of trials included in both groups.

Therefore, our finding should be interpreted with caution. Due to the lack of research examining the effect of coping interventions helping women manage the latent phase of labour, we are limited to making comparisons with other trials and reviews. Probably this is because the duration and the exact connotations of the latent phase of labour have not yet been established [1], and so trials focused on it may be particularly hard to plan. However, a recent Cochrane review on the relaxation technique for pain management in labour [23] suggested that relaxation techniques may be a helpful strategy for pain management in labour. Similarly, we found out that mindfulness interventions may increase women's self-efficacy, while relaxation techniques or music could decrease anxiety or pain levels in the latent phase of labour. The use of manual methods for pain management in labour has already been investigated by Smith et al. [23] in 2012 with a systematic review, but the authors identified only one study focused on the latent phase of labour and expressed the need of further research. In this review we found out that manual methods could be taught during pregnancy (CSTP) or be implemented by the health care providers during labour (CSPL). The CSTP appears to be related to an increase of women's selfefficacy, but they are less effective on women's pain in latent phase. The CSPL appear to be linked to a decrease of pain and anxiety, if delivered directly by the health care providers or the women's partner during the latent phase of labour. There was some evidence in the studies we analyzed that coping strategies could empower women, encouraging them to include the partner for support in labour or reducing the epidural analgesia rate and the maternity ward access during the latent phase of labour. Our findings are consisted with the current literature, which shows a relation between coping strategies and lower levels of perceived stress in women during pregnancy Gloztke et al. [24] or pain in latent phase of labour $[25,26]$.

\section{Overall Completeness and Applicability of Evidence}

This systematic review identified only few trials, mainly with small samples, on interventions or strategies appropriate to help women cope with latent phase of labour. Trials recruited nulliparous and primiparous women, from the third trimester of pregnancy or in latent stage of labour, with the interventions administered in the antenatal clinics or labour ward environment. The completeness and applicability of the evidence is limited to these trials and there is only one well-designed trial at a low risk of bias. Most of the CSTP lack a clear and reproducible description (Table 3). Moreover, the health care providers who administered the interventions were not always clear (Tables $2 \& 3$ ). Trials were not explicit if the health care providers - generally midwives or nurses - providing the CSTP during pregnancy were the same assisting the women during latent phase of labour. Instead, the CSPL were performed by the same health care providers who assisted the women in latent phase of labour. Also, the coping skills and training of the health providers delivering the interventions were not always explicated. Although the effectiveness was not always clear, all the interventions lack harmful side-effects. The primary outcomes were evaluated by self-reported measures in a timing ranging from 30 minutes after birth to one year after the intervention. The majority of trials lacked measurements of all the selected primary outcomes, generally focusing only on one or two between pain, anxiety or self-efficacy. Moreover, most of the trials didn't use validated and specific tools to measure the primary outcomes.

\section{Potential Bias in the Review Process}

We attempted to minimize bias during the review process, and we are aware that some literature on coping strategies or interventions delivered in labour may not be published in indexed journals and therefore may be excluded from the main databases. Our search was limited to studies in English, and we cannot rule out the possibility that some studies may have been missed.

\section{Implication for Practice}

The limited data available suggested that coping interventions could help women manage latent phase of labour. There is no evidence of harm implementing the use of coping strategies in women in latent phase of labour. However, there is insufficient evidence to advise clinical practice yet. Overall there is insufficient data to demonstrate whether coping strategies could help women cope with pain or anxiety in latent phase when used in combination 
with usual care, or whether they are more effective than usual care. Moreover, it is not clear whether it is better to teach coping strategies during pregnancy (CSTP) or to suggest women have it performed for the first time during latent phase (CSPL). There is no clear evidence of who should be the providers teaching or delivering the coping strategies. Due to the unknown risk of bias of in the majority of trials and limited number of trials, further highquality research is needed.

\section{Implication for Research}

Further randomized controlled trials on coping strategies to help women's cope with latent phase should be carried out. The trials should include clinically relevant outcomes, such as those described in this review. The outcomes should be measured by validated and standardized tools, capable of completely catching the complex dimension of women's experience of labour. A methodological issue for trials is the choice of an appropriate control group and a significant sample size. For trials assessing CSPL or CSTP it may be difficult to blind women and midwives, and pragmatic designs should be considered. There is a necessity of improved quality in future trials. In particular, consideration should be given precisely in the description of the interventions and of the health care provider delivering it.

\section{Conflict of Interest}

The authors declare there is no conflict of interest.

\section{Ethical Approval}

This study is a systematic review. It does not require ethical approval.

\section{Funding Source}

No external funding was received for this study.

\section{References}

1. (2018) World Health Organization [WHO]. Intrapartum care for a positive childbirth experience.

2. Friedman E (1978) Labor: clinical evaluation and management. $2^{\text {nd }}$ Edition. Appleton-Century Crofts New York.

3. Carlsson IM, Hallberg LRM, Pettersson KO (2006) Swedish women's experiences of seeking care and being admitted during the latent phase of labour: A grounded theory study. Midwifery 25(2): 172-180.

4. Beebe KR, Humphreys J (2006) Expectations, perceptions and management of labor in nulliparas prior to hospitalization. Journal of midwifery \& women's health 51(5): 347-353.

5. Rota A, Antolini L, Colciago E, Nespoli A, Borrelli SE, et al. (2017) Timing of hospital admission in labour: latent versus active phase, mode of birth and intrapartum interventions. A correlational study. Women \& Birth 31(4): 313-318.

6. Eri TS, Bondas T, Gross MM, Jenssen P, Green JM, et al. (2015) A balancing act in an unknown territory: A metasynthesis of first-time mothers' experiences in early labour. Midwifery 31(3): e58-67.

7. Lazarus RS, Folkman S (1984) Stress, appraisal and coping. Springer, New York, USA.
8. Cappelletti G, Nespoli A, Fumagalli S, Borrelli SE (2016) Firts-time mothers' experiences of early labour in Italian maternity care services. Midwifery 34: 198-204.

9. Guardino CM, Dunkel Schetter C (2014) Coping during pregnancy: a sstematic review and recommendations. Health psychology review 8(1): 70-94.

10. Angeby K, Wilde Larsson B, Hildingsson I, Sadin Bojo AK (2018) Prevalence of prolonged latent phase and labor outcomes: review of birth records in a Swedish population. Journal of Midwifery \& Women's health 63(1): 33-44.

11. Egger M, Smith GD (2008) Principles of and procedures for systematic reviews. In: M Egger, GD Smith, DG Altman (Edn's.) Systematic reviews in health care: Meta-Analysis in Context 23-42. Hoboken: BMJ Publishing Group.

12. Moher D, Liberati A, Tetzlaff J, Altman DG, The PRISMA Group (2009) Preferred Reporting Items for Systematic Reviews and Meta-Analyses: The PRISMA Statement. PLoS Med 6(7): e1000097.

13. Higgins JPT, Savović J, Page MJ, Sterne JAC (2018) Revised Cochrane riskof-bias tool for randomized trials (RoB 2).

14. (2018) World Health Organization Reproductive Health Library. WHO recommendation on definitions of the latent and active first stages of labour.

15. Duncan LG, Cohn MA, Chao MT, Cook JG, Riccobono J, et al. (2017). Benefits of preparing for childbirth with mindfulness training: a randomized controlled trial with active comparison. BMC pregnancy \& childbirth 140(17): 1-11.

16. Maimburg RD, Vaeth M, Durr J, Hvidman L, Olsen J (2010) Randomized trial of structured antenatal training sessions to improve birth process. An international journal of general obstetrics 117(8): 921-928.

17. Chang MY, Wang SY, Chen CH (2002) Effects of massage on pain and anxiety during labour: a randomized controlled trial in Taiwan. Issues and innovation in nursing practice 38(1): 68-73.

18. Ip WY, Tang CSK, Goggins WB (2009) An educational intervention to improve women's ability to cope with childbirth. Journal of clinical nursing 18(15): 2125-2135.

19. Liu YH, Chang MY, Chen CH (2010) Effects of music therapy on labour and anxiety in Tawaines first-time mothers. Journal of clinical nursing 19(7): 1065-1072.

20. Rahimparvar SFV, Hamzehkhan M, Geranmayeh M, Rahimi R (2012) Effect of educational software on self-efficacy of pregnant women to cope with labour: a randomized controlled trial. Archives of gynecology and obstetrics 286(1): 63-71.

21. Escott D, Slade P, Spiby H, Fraser RB (2005) Preliminary evaluation of a coping strategy enhancement method of preparation for labour. Midwifery 21(3): 278-291.

22. Kimber, McNabb M, Mc Court C, Haines A, Brocklehurst P, et al. (2008) Massage or music for pain relief in labour: a pilot randomized placebocontrolled trail. European Journal of pain 12(8): 961-969.

23. Smith CA, Levett KM, Collins CT, Jones L, (2012) Massage, reflexology and other manual methods for pain management in labour. Cochrane database of systematic review 15(2): CD009290.

24. Goletzke J, Kocalevent RD, Hansen G, Rose M, Becher H, et al. (2017) Prenatal stress perception and coping strategies: insights from a longitudinal prospective pregnancy cohort. Journal of psychosomatic research 102: 8-14.

25. Arendt KW, Tessmer Tuck JA (2013) Nonpharmacologic labor analgesia. Clinics in perinatology 40(3): 351-371.

26. Van der Gucht N, Lewis K (2015) Women's experiences of coping with pain during childbirth: a critical review of quality research. Midwifery 31(3): 349-358. 
ISSN: 2574-1241

DOI: $10.26717 /$ BJSTR.2020.24.004020

Maria Luisa Rega. Biomed J Sci \& Tech Res

(c) 9 This work is licensed under Creative

Submission Link: https://biomedres.us/submit-manuscript.php

$\begin{array}{ll}\text { BIOMEDICAL } & \text { Assets of Publishing with us } \\ \text { RESEARCHES } & \text { - Global archiving of articles } \\ \text { - Immediate, unrestricted online access }\end{array}$

